\title{
Increased mRNA expression of key cytokines among suspected cases of Pneumocystis jirovecii infection
}

Mohammad Y. Alshahrani ${ }^{1}$, Mohammed Alfaifi ${ }^{1}$, Mesfer Al Shahrani ${ }^{1}$, Abdulaziz S. Alshahrani ${ }^{2}$, Ali G. Alkhathami ${ }^{1}$, Ayed A. Dera', Irfan Ahmad', Shadma Wahab ${ }^{3}$, Mirza M. A. Beg ${ }^{4}$, Ali Hakamy ${ }^{5}$ and Mohamed E. Hamid ${ }^{*}$

\begin{abstract}
Background: Pneumocystis pneumonia (PCP) is a fatal infectious disease caused by Pneumocystis jirovecii (PJP). The major factor relevant to morbidity and mortality seems to be the host inflammatory reaction. The objective of this study was to evaluate the role of IL-2, IL-4, IL-10, and IL-13 cytokine mRNA expression among suspected P. jirovecii infection.

Methods: This was a cross-sectional analytical study undertaken in Aseer region, Saudi Arabia. One hundred suspected PCP cases and 100 healthy controls were included in the study. Basic clinical manifestations, radiological findings, microbiological and immunological findings were extracted from the hospital records from January 2019 to August 2019, Pneumocystis detection was done by immune-fluorescent staining (IFAT, Gomorimethanamine silver staining (GMSS), Giemsa staining, Toluidine blue O (TBO), and Pneumocystis RT-PCR.

Results: Increased more than 5 fold, 3 fold, 4 fold, and 7 fold of IL-2, IL-4, IL-10, and IL-13 mRNA expression were observed in PCP cases compared to controls. Higher expression of IL-2 mRNA was connected with crept, wheezing and chest X-ray findings like central perihilar infiltrate, patchy infiltrate, consolidation, hilar lymphadenopathy, pneumothorax, pleural effusion which showed higher expression compared to counterpart ( $p<0.0001)$. Higher expression of IL-4 mRNA was found to be significantly associated with weight loss ( $p=0.002)$, dyspnea $(p=0.003)$, crept $(p=0.01)$, and chest $X$-ray findings $(p<0.0001)$. Significantly increased expression of IL-10 mRNA was observed to be associated with weight loss, dyspnea, night sweats, wheezing, and different findings of chest X-ray compared to their counterparts, whereas, IL-13 mRNA was observed in cases with fever. Suspected cases of PCP confirmed positive by IFTA with higher IL-2, IL-4, and IL-10 mRNA expression compared to negative cases. RT-PCR confirmed PCP cases had significantly higher expression of IL-2, IL-4, and IL-10 as well as IL-13 mRNA compared to negative cases. Positive detected cases by GMSS showed higher IL-2, IL-10 mRNA expression, while Giemsa showed only higher IL-4 mRNA expression compared to negative cases.

Conclusion: Confirmed cases of P. jirovecii showed higher IL-2, IL-4, IL-10, and IL-13 mRNA expression comparatively to negative cases. Increased expression of cytokines may be indicative of infection severity and could help in patients' management.
\end{abstract}

Keywords: Immune-compromised, Interleukins (ILs), Immune-fluorescent staining, PCR, Saudi Arabia

\footnotetext{
* Correspondence: mehamid3@gmail.com

${ }^{6}$ Department of Microbiology and Clinical Parasitology, College of Medicine, King Khalid University, Abha, Saudi Arabia

Full list of author information is available at the end of the article
}

C C The Author(s). 2021 Open Access This article is licensed under a Creative Commons Attribution 4.0 International License, which permits use, sharing, adaptation, distribution and reproduction in any medium or format, as long as you give appropriate credit to the original author(s) and the source, provide a link to the Creative Commons licence, and indicate if changes were made. The images or other third party material in this article are included in the article's Creative Commons licence, unless indicated otherwise in a credit line to the material. If material is not included in the article's Creative Commons licence and your intended use is not permitted by statutory regulation or exceeds the permitted use, you will need to obtain permission directly from the copyright holder. To view a copy of this licence, visit http://creativecommons.org/licenses/by/4.0/ The Creative Commons Public Domain Dedication waiver (http://creativecommons.org/publicdomain/zero/1.0/) applies to the data made available in this article, unless otherwise stated in a credit line to the data. 


\section{Background}

Pulmonary infection, exclusively PCP, is a substantial contributing agent for disastrous diseases [1]. P. jirovecii is the contributing cause of PCP [2]. PCP has been a potentially lethal disease in immune-compromised patients [3]. The clinical appearance of PCP cases comprising clinical and radiological variability, management response, and consequences can be diverse broadly [4]. Several appearances of evidence recommend that the foremost causative factor for morbidity and mortality of PCP patients seems to be the host inflammatory reaction to infectious organisms rather than the organism itself [5].

Type-1 immune response encompasses the generation of Th1 cells-related cytokines, arousing macrophage beginning, the genesis of cytotoxic CD4+ T cells, and the release of antibodies for opsonizing, delayed-type hypersensitivity $[6,7]$.

Th1 is a group of indispensable cells that participated in cytokine production, cell-mediated inflammation, delayed-type hypersensitivity responses, and reflection to be crucial for immunity against intracellular pathogens [8-10]. IL-2 stimulates activation of macrophage cytotoxic CD4+ $\mathrm{T}$ cell generation, antibody production for opsonizing, and $\mathrm{T}$ cell-mediated hypersensitivity reactions [11]. The generation of IL-10 is, therefore, vital for the control of Th1-mediated immune pathology as well as molecular proceedings that control its stimulation and numerous cytokines increase IL-10 levels by Th1 cells [12], and Interleukin-4 (IL-4) has also been involved in causing the up-regulation of IL-10 production [13]. IL-10 participates in the regulation and expansion of Th cells and innate immune responses [6-8].

Th2 cells participate in the defense system against multicellular parasites and their contribution in allergies and atopic illnesses, Th2 cells function has been observed in epithelial tissues, especially the intestinal tract and lungs [14]. Th2 cell population is best documented for the production of IL-4, IL-5, and IL-13 [15]. IL-4 is a multifunctional, pleiotropic cytokine, which is primarily secreted by activated Th2 cells, as well as by mast cells, basophils, eosinophils, and $\gamma \delta \mathrm{T}$ cells [16]. In the adaptive immune system, IL-4 has been a critical endurance factor for lymphocytes and B cells; it encourages plasma cell differentiation and IgG1 and IgE antibody switching [17]. Th1 and Th2 cells contribute to adaptive immunity as well as the role of regulatory $\mathrm{T}$ cells (Treg), which has been established against fungal infection. Treg cells diminish Th1 response, reduce inflammation, promote infection tolerance, and induce reinfection resistance [11]. The phagocytic antifungal action involves oxidative and non-oxidative processes and could be augmented by opsonization and T-cells' cytokines [8]. Therefore, this study targeted to evaluate the role of
IL-2, IL-4, IL-10, and IL-13 cytokine mRNA expression among the suspected cases of respiratory symptoms of $P$. jirovecii infection.

\section{Methods}

\section{Design and setting}

The present study was a cross-sectional analytic study undertaken in Aseer Central Hospital, Khamis Mushayt General Hospital, two tertiary care centers, and the College of Applied Medical Science, King Khalid University, Aseer region, southern Saudi Arabia, between January 2019 and August 2019.

\section{Study population}

Based on the prevalence of the disease (30.3\%) [18], the size of the study population was computed by using the formula, $\mathrm{n}=\mathrm{Z} \alpha^{2}(\mathrm{p} \times \mathrm{q}) / \mathrm{D}^{2}$. Initially the study cohort included 100-suspected PCP cases and further, we confirmed the positive cases by IFAT technique and 100 healthy controls. A written consent was obtained from all study participants. Essential clinical manifestations, radiological findings, microbiological and immunological findings from PCP cases attending Aseer Central Hospital from January 2019 to August 2019 were collected directly from patient charts.

PCP suspected cases who reported having regular respiratory symptoms like breath rapidity, pain in the chest, cough, and interstitial pulmonary infiltrates in X-ray or CT scan were included. The clinical outcome and clinical history of the suspected PCP cases were recorded.

Pneumocystis detection was done by reference diagnostic test methods such as immune fluorescent staining (IFAT) using the Merifluor DFA immunofluorescence test performed by following the manufacturer's provided protocol (Meridian Bioscience, Inc., Cincinnati, Ohio). Other staining diagnostic techniques, like Gomorimethanamine silver staining (GMSS), Giemsa staining, Toluidine blue O (TBO), as well as Pneumocystis RT-PCR were used [19] to detect the Pneumocystis.

\section{Total RNA extraction and cDNA synthesis}

$3 \mathrm{ml}$ of peripheral blood samples were withdrawn from suspected cases of PCP as well as from healthy control subjects. Total RNA extraction from the blood sample was executed using the QIAamp DNA Mini Kit (Qiagen, Germany) following instructions. The quality and quantity of total RNA were determined by the A260/280 ratio using the nano-spectrophotometer method.100 ng total RNA was taken to synthesize the cDNA by kit providedmethod (Verso, Thermo Scientific, USA) for IL-2, IL-4, IL-10, IL-13 mRNA expression following the manufacturer's protocol. 


\section{Cytokine mRNA expression}

Quantitative real-time PCR (qPCR) was performed to quantify the expression of Th1 and Th2 cell cytokines such as IL-2, IL-4, IL-10, IL-13 mRNA expression and glyceraldehyde-3-phosphate dehydrogenase (GAPDH) taken as a reference control to standardize the expression. The reaction was performed in a $25-\mu \mathrm{l}$ reaction amount using the following program: $95^{\circ} \mathrm{C}$ for $5 \mathrm{~min}$, following 40 cycles of amplification, denaturation at $95^{\circ} \mathrm{C}$ for $20 \mathrm{~s}$, annealing (Table 1 ) at $58^{\circ} \mathrm{C}-60^{\circ} \mathrm{C}$ for 30 $\mathrm{s}$, and elongation at $72^{\circ} \mathrm{C}$ for 30s using maxima SYBR green qPCR master mix technology. A melting curve was generated by programming fluorescent measurements every $1{ }^{\circ} \mathrm{C}$ from $35^{\circ} \mathrm{C}$ until $95^{\circ} \mathrm{C}$ to make sure a single PCR product.

\section{Statistical analysis}

The statistical analysis was executed using Graph Pad Prism version 6.05. The Mann - Whitney U test was used for nonparametric data, and t-test was performed for parametric data to compute the significant differences among the groups. QRT-PCR data was performed by the relative cycle threshold $(\mathrm{Ct})$ method, and all samples were examined in triplicate. IL-2, IL-4, IL-10, and IL-13 mRNA expression levels were calculated by the relative quantification method using the $2^{-(\Delta \Delta \mathrm{Ct})}$ method [20]. Results more than or less than 1 were taken to indicate for up-regulation or down-regulation of mRNA expression. All the values were standardized compared to the normal control values, represented as a value of 1 . $P$-value $\leq 0.05$ was considered significant.

\section{Results}

Demographic and clinical features of study participants The present study included 200 study subjects. Among them, 100 were suspected cases of PCP, and 100 were healthy controls. Among the suspected cases of PCP, $59 \%$ were males and $41 \%$ were females, while among the healthy controls, $55 \%$ were males and $45 \%$ were females.
Two age groups were determined based on the mean age of all study participants, $<50$ years of age group cases were $45 \%$, while $>50$ years of age group cases were $55 \%$, while in healthy controls $<50$ years of age group healthy controls were $48 \%$ while $>50$ years of age group of healthy controls were $52 \%$. As shown in Table 2, all suspected cases had cough (100\%), 92\% had fever, $80 \%$ had weight loss, $76 \%$ had dyspnea, and $54 \%$ had night sweats, which was the most common clinical manifestation of PCP cases. 62 and 75\% suspected cases of PCP had crept and wheezing, respectively. Chest X-ray showed multiple pulmonary findings, and the most common was pulmonary infiltrates (Fig. 1).

\section{Cytokine IL-2 mRNA expression}

Increased mRNA expression of IL-2 (5.72 fold) was observed in suspected cases of PCP compared to healthy controls (Table 2). Significantly increased expression of IL-2 mRNA was associated with crept wheezing and chest X-ray findings. Patients who had a clinical feature like crept showed 6.30 fold IL-2 mRNA expression, while patients with no crept showed 4.68 fold IL-3 mRNA expression, and the differences among them were found to be significant $(p=0.0007)$. Patients findings like wheezing showed 6.30 fold IL-3 mRNA expression, while patients without wheezing showed 3.96 fold IL-2 mRNA expression $(p=0.001)$. Patient's chest X-ray findings showed central perihilar infiltrate (7.59 fold), patchy infiltrate (9.98 fold), consolidation (5.73 fold), hilar lymphadenopathy (6.62 fold), pneumothorax (5.28 fold), pleural effusion (6.54 fold) showed higher expression of IL-2 mRNA expression compared to those patients did not show any such findings in X-ray (4.61 fold), and differences among them were found to be statistically significant $(p<0.0001)$.

\section{Cytokine IL-4 mRNA expression}

IL-4 mRNA expression was 4.35 fold higher among the cases compared to healthy controls (Table 2). Higher

Table 1 PCR primers sequences

\begin{tabular}{|c|c|c|c|}
\hline Gene name & Primer sequence & Annealing temperature & Product length $(b p)$ \\
\hline \multirow[t]{2}{*}{ IL - 2} & FP: 5'-AACCTCAACTCCTGCCACAA-3' & $60^{\circ} \mathrm{C}$ & 197 \\
\hline & RP: 5'-GCATCCTGGTGAGTTTGGGA-3' & & \\
\hline \multirow[t]{2}{*}{ IL -4} & FP: 5'-CACAACTGAGAAGGAAACCTTCTG-3' & $60^{\circ} \mathrm{C}$ & 253 \\
\hline & RP: 5'-CTCTCTCATGATCGTCTITAGCCTITC-3' & & \\
\hline \multirow[t]{2}{*}{ IL - 10} & FP: 5'-AGAACCT GAAGACCCTCAGGC-3' & $60^{\circ} \mathrm{C}$ & 78 \\
\hline & RP: 5'-CCACGGCCTTGCTCTTGTT-3' & & \\
\hline \multirow[t]{2}{*}{ IL -13} & FP: 5'-GCTCCTCAATCCTCTCCTGTT-3' & $58^{\circ} \mathrm{C}$ & 485 \\
\hline & RP: 5'-GCAACTTCAATAGTCAGGTCC-3' & & \\
\hline \multirow[t]{2}{*}{ GAPDH } & FP: 5'-GAAGGTGAAGGTCGGAGTC-3' & $60^{\circ} \mathrm{C}$ & 226 \\
\hline & RP: 5'-GAAGATGGTGATGGGATTTC-3' & & \\
\hline
\end{tabular}


Table 2 Demographic and clinical characteristics of study subjects and the relative expressions of IL-2, IL-4, IL-10, and IL-13 mRNAs among Pneumocystis pneumonia (PCP) cases compared to healthy controls

\begin{tabular}{|c|c|c|c|c|c|c|c|c|c|}
\hline Variables & $\begin{array}{l}\text { No. of } \\
\text { PCP } \\
\text { cases }\end{array}$ & $\begin{array}{l}\text { No. of } \\
\text { healthy } \\
\text { controls }\end{array}$ & $\begin{array}{l}\text { IL-2 mRNA } \\
\text { expression } \\
(\text { Mean } \pm \text { SD) }\end{array}$ & $\begin{array}{l}p- \\
\text { value }\end{array}$ & $\begin{array}{l}\text { IL-4 mRNA } \\
\text { expression } \\
\text { (Mean +SD) }\end{array}$ & $\begin{array}{l}p- \\
\text { value }\end{array}$ & $\begin{array}{l}\text { IL-10 mRNA } \\
\text { expression } \\
\text { (Mean +SD) }\end{array}$ & $\begin{array}{l}p \text { - } \\
\text { value }\end{array}$ & $\begin{array}{l}\text { IL-13 mRNA } \\
\text { expression } \\
\text { (Mean +SD) }\end{array}$ \\
\hline Overall & 100 & 100 & $5.72 \pm 3.16$ & - & $4.35 \pm 4.20$ & - & $3.77 \pm 2.99$ & - & $7.59 \pm 4.82$ \\
\hline \multicolumn{10}{|l|}{ Gender } \\
\hline Males & 59 & 55 & $5.70 \pm 3.27$ & 0.57 & $3.91 \pm 3.62$ & 0.39 & $3.37 \pm 2.68$ & 0.20 & $8.0 \pm 4.80$ \\
\hline Females & 41 & 45 & $5.74 \pm 3.03$ & & $4.99 \pm 4.89$ & & $4.35 \pm 3.64$ & & $7.0 \pm 4.85$ \\
\hline \multicolumn{10}{|l|}{ Age (in years) } \\
\hline$<50$ years & 45 & 48 & $5.43 \pm 3.34$ & 0.16 & $3.97 \pm 4.51$ & 0.10 & $3.48 \pm 2.60$ & 0.56 & $7.65 \pm 4.79$ \\
\hline$>50$ years & 55 & 52 & $5.95+3.01$ & & $4.66+3.94$ & & $4.01 \pm 3.28$ & & $7.55 \pm 4.89$ \\
\hline \multicolumn{10}{|l|}{ Cough } \\
\hline Yes & 100 & $N A^{a}$ & $5.72 \pm 3.16$ & - & $4.35 \pm 4.20$ & - & $3.77 \pm 2.99$ & & $7.59 \pm 4.82$ \\
\hline No & 0 & NA & - & & - & & - & & - \\
\hline \multicolumn{10}{|l|}{ Fever } \\
\hline Yes & 92 & NA & $5.80 \pm 3.16$ & 0.23 & $4.40 \pm 4.27$ & 0.65 & $3.81 \pm 3.01$ & 0.71 & $7.88 \pm 4.79$ \\
\hline No & 8 & NA & $4.71 \pm 3.17$ & & $3.79 \pm 3.47$ & & $3.36 \pm 1.60$ & & $4.34 \pm 4.10$ \\
\hline \multicolumn{10}{|l|}{ Weight loss } \\
\hline Yes & 80 & NA & $5.82 \pm 3.16$ & 0.38 & $4.77 \pm 4.12$ & 0.002 & $3.99+2.96$ & 0.02 & $7.74 \pm 4.93$ \\
\hline No & 20 & NA & $5.29 \pm 3.20$ & & $2.66 \pm 4.17$ & & $2.89 \pm 3.03$ & & $7.56 \pm 4.82$ \\
\hline \multicolumn{10}{|l|}{ Dyspnea } \\
\hline Yes & 76 & NA & $5.77 \pm 3.25$ & 0.92 & $4.94+4.47$ & 0.003 & $4.15+3.21$ & 0.01 & $7.57 \pm 4.82$ \\
\hline No & 24 & NA & $5.54 \pm 2.89$ & & $2.49 \pm 2.47$ & & $2.56 \pm 1.70$ & & $7.68 \pm 4.92$ \\
\hline \multicolumn{10}{|l|}{ Night sweats } \\
\hline Yes & 54 & NA & $6.37 \pm 3.68$ & 0.06 & $4.56 \pm 4.16$ & 0.39 & $4.62 \pm 3.60$ & 0.006 & $7.88 \pm 4.58$ \\
\hline No & 46 & NA & $4.95 \pm 2.20$ & & $4.10 \pm 4.27$ & & $2.77 \pm 1.58$ & & $7.26 \pm 5.11$ \\
\hline \multicolumn{10}{|l|}{ Crept } \\
\hline Yes & 62 & NA & $6.35 \pm 3.32$ & 0.007 & $5.0 \pm 4.86$ & 0.01 & $4.16 \pm 3.29$ & 0.09 & $8.01 \pm 5.08$ \\
\hline No & 38 & NA & $4.68+2.60$ & & $3.28 \pm 3.49$ & & $3.13 \pm 2.23$ & & $6.91 \pm 4.33$ \\
\hline \multicolumn{10}{|l|}{ Wheezing } \\
\hline Yes & 75 & NA & $6.30 \pm 3.32$ & 0.001 & $4.87 \pm 5.11$ & 0.98 & $4.06 \pm 3.06$ & 0.007 & $7.98 \pm 5.01$ \\
\hline No & 25 & NA & $3.96 \pm 1.70$ & & $4.17 \pm 3.87$ & & $2.92 \pm 2.63$ & & $6.45 \pm 4.08$ \\
\hline \multicolumn{10}{|l|}{ Chest X-ray } \\
\hline $\begin{array}{l}\text { Central perihilar } \\
\text { infiltrates }\end{array}$ & 19 & NA & $7.59+2.83$ & $\begin{array}{l}< \\
0.0001\end{array}$ & $7.55 \pm 4.67$ & $\begin{array}{l}< \\
0.0001\end{array}$ & $6.11 \pm 4.05$ & $\begin{array}{l}< \\
0.0001\end{array}$ & $9.05 \pm 5.03$ \\
\hline Patchy infiltrates & 8 & NA & $9.88 \pm 5.12$ & & $3.46 \pm 1.98$ & & $5.40 \pm 3.63$ & & $7.30 \pm 4.30$ \\
\hline Consolidation & 3 & NA & $5.73 \pm 1.0$ & & $2.94 \pm 0.80$ & & $5.50 \pm 4.83$ & & $13.40 \pm 7.45$ \\
\hline $\begin{array}{l}\text { Hilar } \\
\text { lymphadenopathy }\end{array}$ & 3 & NA & $6.62 \pm 2.05$ & & $5.87 \pm 0.63$ & & $5.02 \pm 2.47$ & & $5.69 \pm 4.13$ \\
\hline Pneumothorax & 1 & NA & 5.38 & & 1.08 & & 1.67 & & 5.09 \\
\hline Pleural effusion & 1 & NA & 6.54 & & 14.22 & & 0.30 & & 14.62 \\
\hline No & 65 & NA & $4.61 \pm 2.37$ & & $3.41 \pm 3.84$ & & $2.83+1.88$ & & $6.95 \pm 4.57$ \\
\hline
\end{tabular}

${ }^{\mathrm{a}} \mathrm{NA}$ Not applicable

expression of IL-4 mRNA was found to be significantly associated with weight loss $(p=0.002)$, dyspnea $(p=$ $0.003)$, crept $(p=0.01)$, and chest $\mathrm{X}$-ray findings $(\mathrm{p}<$ $0.0001)$. Cases with weight loss, dyspnea, crept had 4.77 fold, 4.94 fold, 5.0 fold IL-4 mRNA expression, while cases with no weight loss, dyspnea, crept showed 2.66 fold, 2.49 fold, 3.28 fold IL-4 mRNA expression, respectively, which is lower compared to counterpart. Cases 


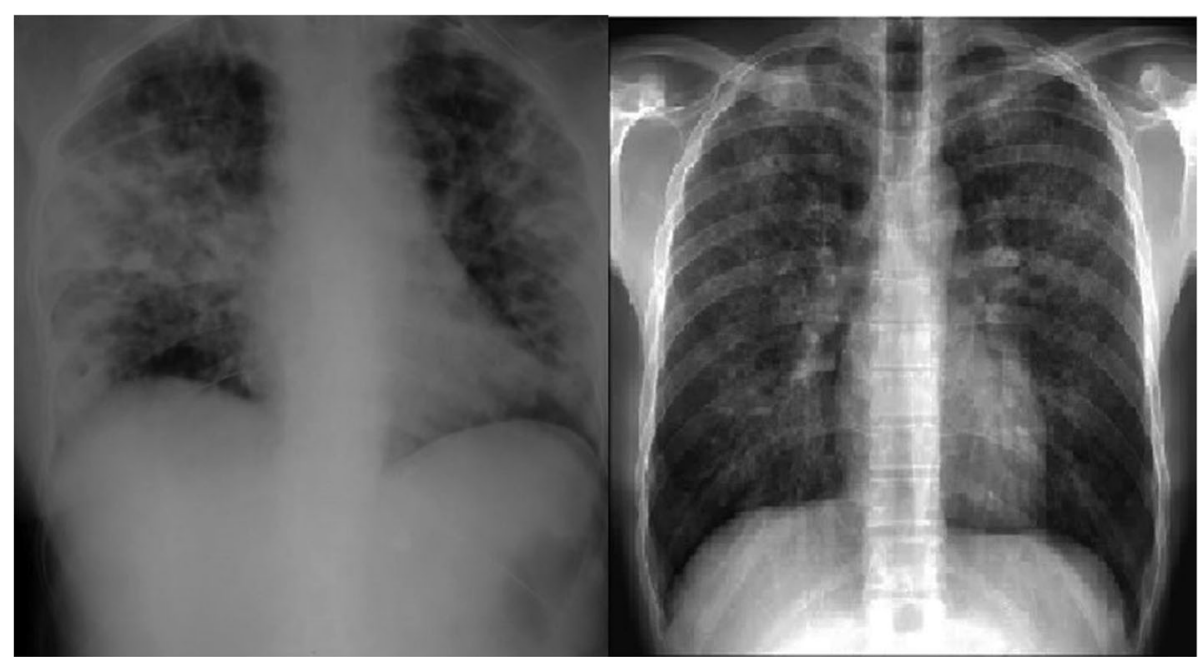

Fig. 1 X-ray presentation of PCP positive patients showing multiple pulmonary involvement with massive pulmonary infiltrates

with different findings in X-rays such as central perihilar infiltrate, patchy infiltrate, consolidation, hilar lymphadenopathy, pneumothorax, pleural effusion showed 7.55 fold, 3.46 fold, 2.94 fold, 5.87 fold, 1.08 fold, 14.22 fold, respectively.

\section{Cytokine IL-10 mRNA expression}

Overall, 3.77 fold increased IL-10 mRNA expression was observed among the cases compared to healthy controls (Table 2). Significantly higher expression of IL-10 mRNA was found to be associated with weight loss $(p=0.02)$, dyspnea $(p=0.01)$, night sweats $(p=0.006)$, wheezing ( $p=$ $0.007)$, and different findings of chest X-ray $(p<0.0001)$. Patients who had weight loss had 3.99 fold IL-10 mRNA expression, dyspnea had 4.15 fold IL-10 mRNA expression, night sweat had 4.62 fold IL-10 mRNA expression, and wheezing had 4.06 fold IL-10 mRNA which is higher compared to counterpart. Patient's chest X-ray findings such as central perihilar infiltrate, patchy infiltrate, consolidation, hilar lymphadenopathy had higher IL-10 mRNA expression comparatively to other findings.

\section{Cytokine IL-13 mRNA expression}

Increased mRNA expression of IL-13 (7.59 fold) was observed among the cases compared to healthy controls (Table 2). A significant association of IL-13 mRNA was observed in cases with fever $(p=0.02)$. Cases with fever showed 7.88 fold higher IL-13 mRNA expression, while cases without fever showed 4.34 fold IL-13 mRNA expression, while no such association was observed with other clinical findings.

\section{PCP detection by IFAT and cytokine mRNA expression}

Suspected cases of PCP were detected by the IFAT stain, and $35 \%$ were observed to be positive, and $65 \%$ were negative (Fig. 2). The 35\% positive cases showed 7.78 fold IL-2 mRNA expression, 5.51 fold IL-10 mRNA expression, 6.08 fold mRNA expression, and 8.78 fold IL13 mRNA expression. In comparison, $65 \%$ of negative cases showed 4.61 fold IL-2 mRNA expression, 2.83 fold IL-10 mRNA expression, 3.41 fold mRNA expression, and 6.95 fold IL-13 mRNA expression, respectively lower compared to its counterpart and differences among cytokines were found to be significant except IL-13 mRNA expression.

\section{PCP detection by GMSS and cytokine mRNA expression}

GMSS stain showed 15 (42.86\%) positive cases out of 35 positive cases confirmed by IFAT for PCP, and others were negative (Fig. 3). Cytokines mRNA expression such as IL-2 $(p=0.001)$ and IL-10 ( $p=0.004)$ showed a significant difference among the groups, while IL-4 and IL-13 did not show any significant difference. PCP positive cases by GMSS stain showed 8.37 fold IL- 2 mRNA expression, 5.56 fold IL-10 mRNA expression, while negative cases showed 5.25 fold IL-2 mRNA expression, 3.45 fold IL-10 mRNA expression. Positive cases by GMSS had 5.23 fold IL-4 mRNA expression, 8.43 fold IL-13 mRNA expression, while negative cases for PCP by GMSS had 4.19 fold IL-4 mRNA expression and 7.45 fold IL-13 mRNA expression.

\section{PCP detection by Giemsa and cytokine mRNA expression} Giemsa stain showed 8 (17.6\%) positive cases out of 35 positive cases confirmed by IFAT for PCP, and others were negative (Fig. 4). No such significant differences were reported in cytokine mRNA expression among the groups except IL-4 mRNA expression $(p=0.04)$. Positive cases for PCP by Giemsa stain showed 6.21 fold IL-4 


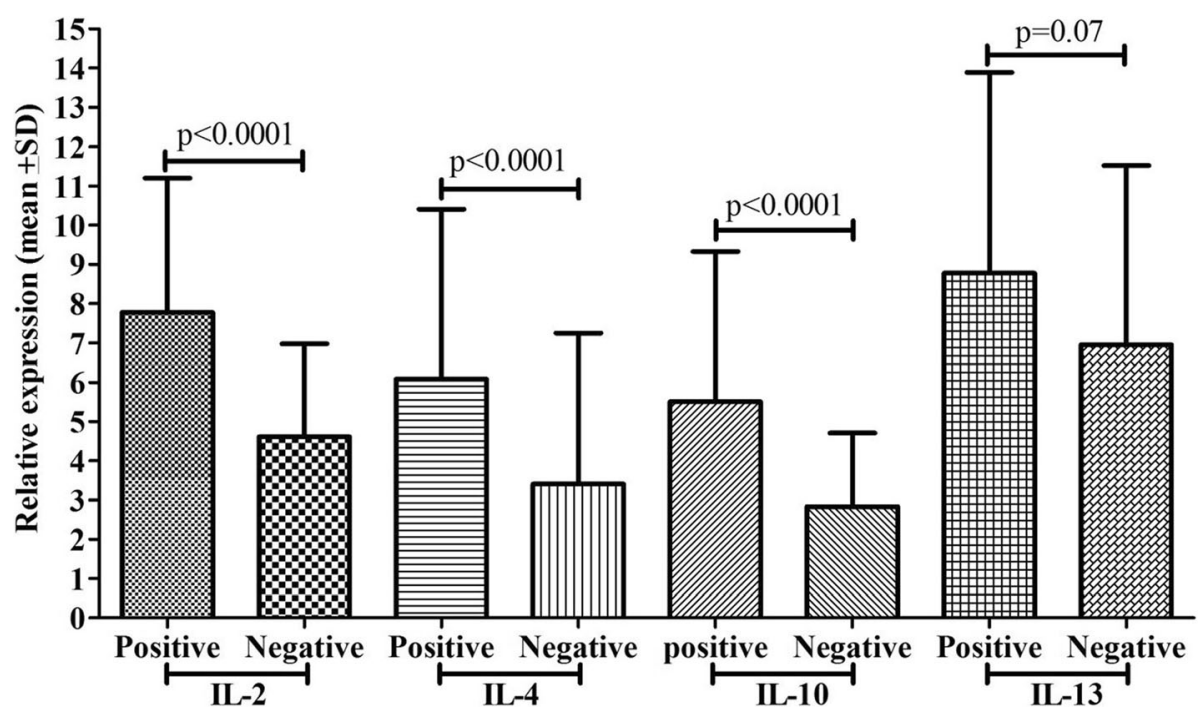

Fig. 2 Comparison of cytokine mRNA expression (IL-2, IL-4, IL-10, and IL-13) between PCP positive and negatives cases by IFAT

mRNA expression, while negative patients showed 4.16 fold IL-4 mRNA expression.

\section{PCP detection by TBO and cytokine mRNA expression}

TBO stain showed $1(2.8 \%)$ positive cases out of 35 positive cases confirmed by IFAT for PCP, and others were negative (Fig. 5). No significant differences were found in the expression of IL-2, IL-4, IL-10, and IL-13 mRNA expression between the positive and negative detected cases of PCP.

PCP detection by RT-PCR and cytokine mRNA expression Detection of PCP was done by RT-PCR method, 39 (39\%) of patients had PCP, and 59\% suspected cases were negative for PCP (Fig. 6). PCP confirmed cases showed significantly higher Th1 (IL-2 and IL-10) and Th2 (IL-4 and IL-13) cytokine mRNA expression compared to negative cases. PCP positive cases showed 7.86 fold IL-2, 5.15 fold IL-10, 5.89 fold IL-4, 8.77 fold IL-13 mRNA expression, while negative cases showed 4.38 fold IL-2, 2.89 fold IL-10, 3.36 fold IL-4, 6.84 fold IL-13 mRNA expression and differences among them was found to be significant $(p<0.0001, p<0.0001, p<0.0001$, $p=0.04)$, respectively.

\section{Discussion}

$P$. jirovecii is an opportunistic fungal pathogen confined to lung alveoli that causes pneumonia. Pneumocystis

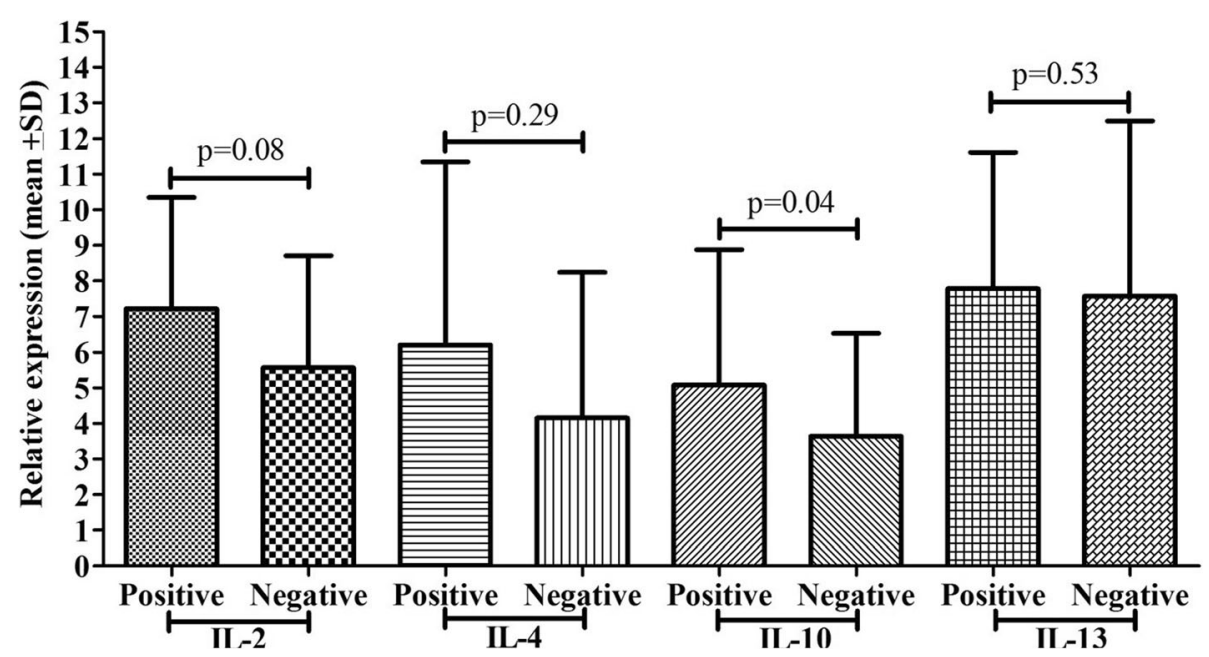

Fig. 3 Comparison of cytokine mRNA expression (IL-2, IL-4, IL-10, and IL-13) between PCP positive and negatives cases by Giemsa 


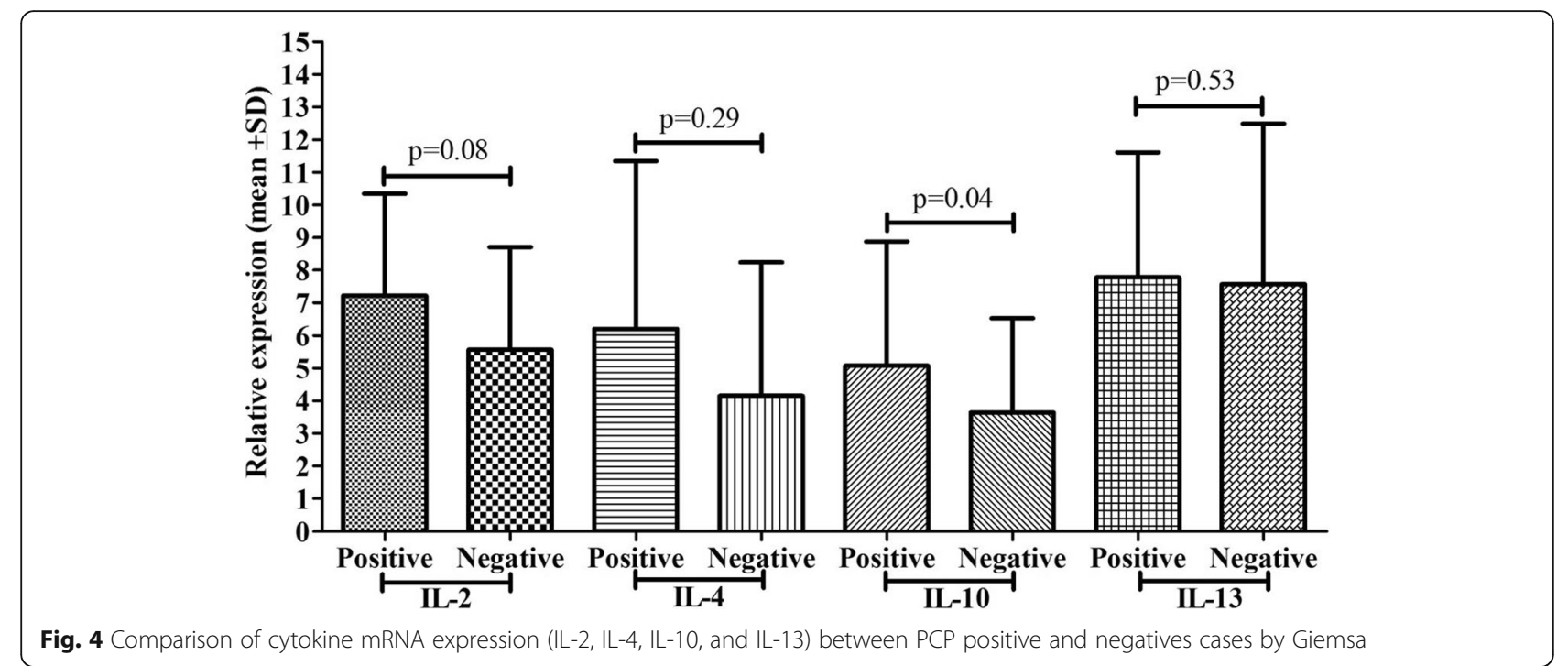

pneumonia remains a common cause of morbidity and death [21]. Activation of cellular effectors is necessary for the clearance of $P$. jirovecii by cytokine and the chemokine networks [3]. Iriart et al. stated that human $P$. jirovecii infection was connected with alterations in cytokine levels while comparing different groups of patients positive and negative for $P$. jirovecii infection [22]. The host immune response during Pneumocystis pneumonia comprises multifaceted interactions among $\mathrm{T}$ cells, alveolar macrophages (AM), neutrophils, and soluble arbiters that facilitate the pathogen's approval as an elevated level of interleukin mRNA [23]. It has been validated that $\mathrm{CD} 4+\mathrm{T}$ lymphocytes have a crucial role in the infection pathogenesis and the opposite connection between the numerals of blood CD4+ lymphocytes and the risk of successive Pneumocystis pneumonia [24]. Cytokine and chemokine networks are essential of $P$. jirovecii approval by the commencement of these effectors. A study performed primarily in murine models showed an essential role for TNF- $\alpha$ or IL-10, two different cytokines in the $\mathrm{T}$ helper response [25].

An earlier study has done to check the mRNA expression level of cytokines of Th cells among the study cases for $P$. jirovecii infection, and further, the diagnosis was made by several methods such as IFAT, GMSS, Giemsa, TBO, and RT-PCR method to confirm the patients and to compare the diagnostic tests [19]. The present study observed more than 5 fold, 3 fold, 4 fold, 7 fold increased mRNA expression of IL-2, IL-10, IL-4, and IL13, respectively, among the cases compared to healthy control subjects. Higher expression of IL-2, IL-10 mRNA was linked with cases that had crept, wheezing, and

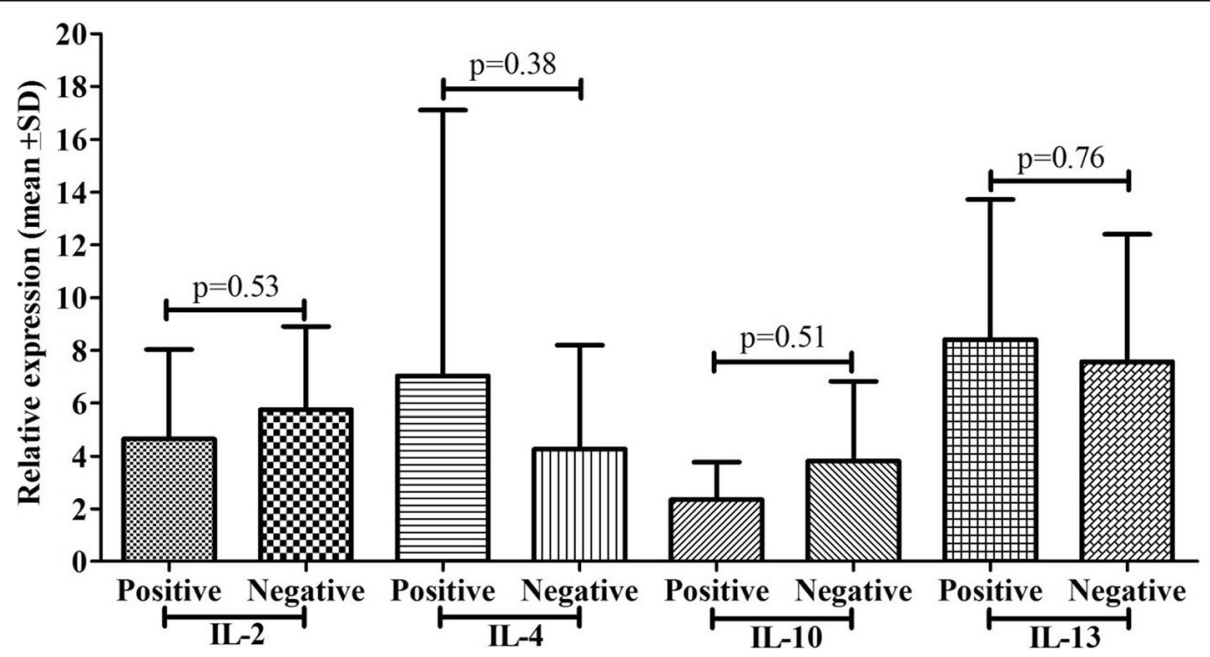

Fig. 5 Comparison of cytokine mRNA expression (IL-2, IL-4, IL-10, and IL-13) between PCP positive and negatives cases by TBO 


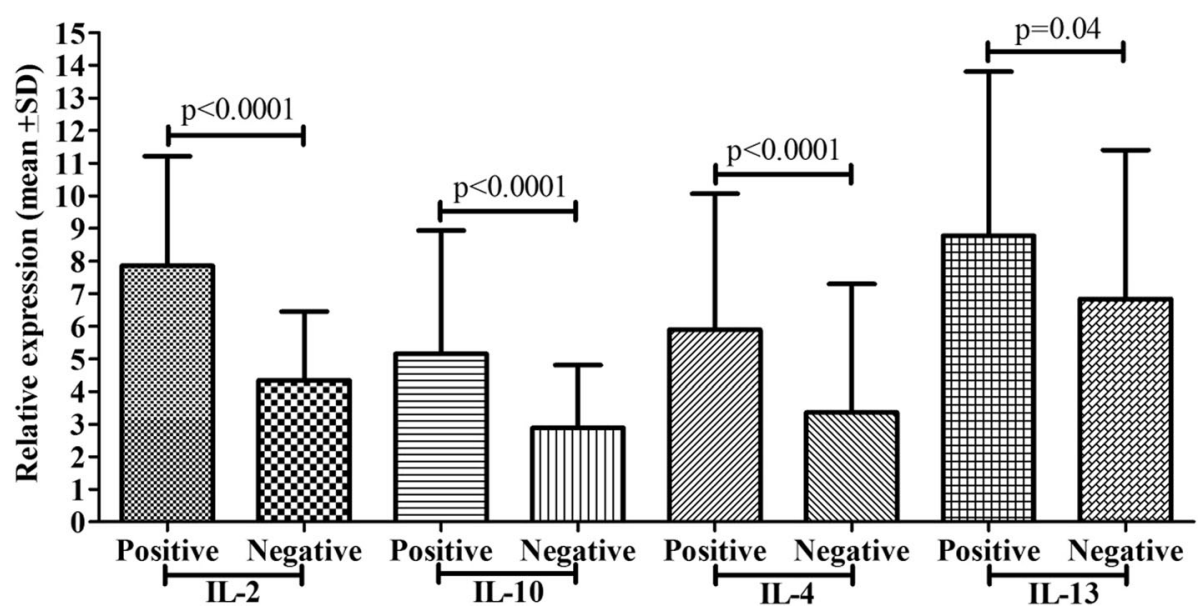

Fig. 6 Comparison of cytokine mRNA expression (IL-2, IL-4, IL-10, and IL-13) between PCP positive and negatives cases by RT-PCR

chest X-ray findings while lower expression in their counterparts comparatively. Besides, the higher expression of IL-10 mRNA was also significantly associated with the cases who had weight loss and dyspnea compared to its counterpart. Higher expression of IL-4 mRNA was associated with cases that had weight loss, dyspnea, crept, and chest X-ray findings, while higher expression of IL-13 mRNA was associated with cases who reported fever.

In adult patients, $P$. jirovecii colonization makes them cause infection and has been depicted with chronic obstructive airway disease [26]. In our study, clinical observations such as cases with cough $(100 \%)$, cases with fever (92\%), cases with unintentional weight loss $(80 \%)$, and cases with dyspnea (76\%) were connected with the risk of PCP and similar findings were also reported [27].. PCP positive patients had $85.7 \%$ typical interstitial pulmonary infiltrates consistently observed in chest X-ray findings. A similar study reported that pulmonary infiltrates were observed in $89.5 \%$ of patients, and $84.2 \%$ showed bilateral pulmonary infiltrates [28]. Chronic inflammatory disorder was explained by airflow limitation, which linked to a multifaceted inflammatory response in the lungs. Colonization of $P$. jirovecii infection in the lung tissue can cause pulmonary tissue damage and the deterioration of lung function through inflammation and the related inflammatory arbitrator. Therefore, $P$. jirovecii colonization influences disease progression [29].

PCR methods for the diagnosis of PCP in bronchoalveolar lavage fluid have shown good sensitivity and specificity. These authors have encouraged the use of clinical practice, radiography as well as laboratory findings of suspected patients for a definitive diagnosis of PCP [30]. Based on different diagnostic methods used to detect the $P$. jirovecii infection such as IFTA, GMSS, Giemsa, TBO, and RT-PCR methods. Two groups were made based on the positive and negative detection of $P$. jirovecii in suspected cases. Cytokine mRNA expression was evaluated and compared for the groups confirmed positive and negative for $P$. jirovecii. Cases that were positive for $P$. jirovecii by the IFTA method showed significantly higher IL2, IL-10, and IL-4 mRNA expression levels than negative cases. Elevated expression of IL-2, IL-10 mRNA was detected in cases positive for $P$. jirovecii by GMSS method, while negative showed comparatively low mRNA expression. Positive cases for $P$. jirovecii by the Giemsa method only showed higher mRNA expression of IL-14 than its cases. In contrast, cases detected positive for $P$. jirovecii and negative for PCP by TBO method did not show any differences in cytokine mRNA expression. Cases reported positive for $P$. jirovecii by RT-PCR method showed significantly higher IL-2, IL-10, IL-4, and IL-13 mRNA expression compared to negative cases of PCP.

Write and colleagues revealed that T-cells play a decisive role in inflammation stimulation in feedback to Pneumocystis infection, inducing elevated levels of cytokine mRNA at sites of infection and acute alveolar inflammation [23]. Fungal or microbial infections connected with granulomatous inflammatory and depend on coordinated communication of innate and adaptive immune reactions by Th1 response [31]. This defensive immune reaction involves the secretion of cytokines, which leads the classical commencement of macrophages and their recruitment at the site of infection [31, 32]. Higher IL-4, IL10 , and IL-13 levels were observed to be associated with inadequate IFN- $\gamma$ production, and otherwise, activation of macrophages dominant to uncontrolled fungal infection [33, 34] as well as Cenci et al. in 1998 reported that mice infected with fungal pathogens are susceptible to produce an IL-10 and IL-4 [35]. Th2-mediated allergic responses to fungal in mice, resulting in repeated lung exposure to fungal strains, produce IL-4 and IL-13 (Lilly LM et al., 
2012) as well as the intratracheal direction of fungal spores induced allergic asthma in mice [36]. Improved understanding of cytokine expression may be a clue of patients' treatment having infectious diseases.

\section{Limitations}

Control individuals in the present study have been clearly chosen on the absence of symptoms of PCP. Healthy controls who have been included were those who did not show any respiratory symptoms in the last 6 months and any other complications related to the chest or any medication received in the last 6 months. Therefore, it is one of the limitations of the present study that colonization, infection or PCP disease should be discriminated from each other. However, our current methodology cannot reach to this level of discrimination, given the fact that it was not part of the original aims. Definitive diagnosis of PCP requires the demonstration of Pneumocystis in the lungs of a patient with compatible pulmonary signs and symptoms, nevertheless, pneumocystis has remained tenacious to study [37].

Another limitation of this study as for similar studies, is that different diagnostic methods revealed different results [38]. This is obvious and acceptable given the fact that these methods have different sensitivities and specificities and work on a specific part of the fungus or the host immune response [37, 39]. For instance, the Calcofluor white and GMS stains have better results for routine use in a clinical laboratory [38]. Pneumocystis species have a life cycle with both mitotic and meiotic phases analogous to other ascomycetous fungi, but with unique adaptations to interact with host cells and proliferate within the unique niche of the mammalian lung.

\section{Conclusions}

Identifying specific markers and molecular signatures is an important step that will support clinical diagnosis to improve patient's management. $P$. jirovecii patients presented high IL-2, IL-4, IL-10, and IL-13 mRNA expression compared to negative controls. Increased expression of cytokines may be indicative of infection severity and could help in patients' management. The study observed increased IL-2, IL-4, IL-10, and IL-13 mRNA expression in suspected cases of $P$. jirovecii infection. Confirmed cases of $P$. jirovecii showed higher IL-2, IL-4, IL-10, and IL-13 mRNA expression comparatively to negative cases. The present study did not explore TNF alpha and IFN- $\Upsilon$ since these markers have been studied [40-42]. Our study focused on exploring IL-2, IL-4, IL-10, and IL-13 mRNA expression levels which have not been investigated in PCP extensively and they fulfil the diagnostic aims among the studied PCP population in comparison to healthy controls. Increased expression of cytokines may be indicative of infection severity (hypoxia) and could help in patients' management. Monitoring the expression of interleukins may help plan a treatment strategy and overcome the problem of treatment failure and therapy response. Cytokines could open the avenues for fungal infections' treatment of fungal infections.

\section{Abbreviations}

PCP: Pneumocystis pneumonia; PJP: Pneumocystis jirovecii; IL-: Interleukins; mRNA: Messenger RNA; IFAT: Immune-fluorescent staining;

GMSS: Gomorimethanamine silver staining

\section{Acknowledgements}

The authors extend their appreciation to the Deanship of Scientific Research at King Khalid University for funding this work through Group Research Project under grant number G.R.P2/78-40.

\section{Authors' contributions}

Designed the study and wrote the draft manuscript, MYA; analyzed the data, MAS and IA; collected blood samples, MA, ASA and AH; designed primers and tested product purification, $A G A$; conducted $P C R$ protocols, AAD; performed RNA extraction and CDNA synthesis, SW; contributed to reagents, MMAB; wrote and reviewed the final draft of the manuscript, MEH. All authors read and approved the manuscript.

\section{Funding}

This project was supported by the Deanship of Scientific Research, King Khalid University, under grant number G.R.P2/78-40. The funder had no part in the collection of data, construction of the study concept, analysis of data, interpretation of data, writing of the manuscript, or the idea to submit the manuscript for publication.

\section{Availability of data and materials}

The datasets used and/or analyzed during the current study are available from the corresponding author on reasonable request.

\section{Ethics approval and consent to participate}

The Research Ethics Committee Deanship of Scientific Research, King Khalid University, Abha, Kingdom of Saudi Arabia, approved the present research work with reference approval number (ECM-2019-73). Upon this approval, data were collected directly from patient charts. Written consent was obtained from all study participants.

\section{Consent for publication}

Not applicable.

\section{Competing interests}

The authors declare that they have no competing interests. None of the authors have financial and nonfinancial conflicts of interest.

\section{Author details}

'Department of Clinical Laboratory Sciences, College of Applied Medical Sciences, King Khalid University, Abha, Saudi Arabia. ${ }^{2}$ Department of Medicine, Faculty of Medicine, Najran University, Najran, Saudi Arabia. ${ }^{3}$ Department of Pharmacognosy, College of Pharmacy, King Khalid University, Abha, Saudi Arabia. ${ }^{4}$ Department of Biochemistry, Maulana Azad Medical College, New Delhi, India. ${ }^{5}$ Respiratory Therapy Department, Faculty of Applied Medical Sciences, Jazan University, Jazan, Saudi Arabia. ${ }^{6}$ Department of Microbiology and Clinical Parasitology, College of Medicine, King Khalid University, Abha, Saudi Arabia.

Received: 30 July 2020 Accepted: 21 December 2020

Published online: 07 January 2021

\section{References}

1. Hirama T. A real-time PCR-based diagnostic test for organisms in respiratory tract infection. Polymerase chain reactions for biomedical applications. IntechOpen Limited, London, UK: Intech Open Science; 2016.

2. Mühlethaler K, Bögli-Stuber K, Wasmer S, von Garnier C, Dumont P, Rauch A, Mühlemann K, Garzoni C. Quantitative PCR to diagnose Pneumocystis 
pneumonia in immunocompromised non-HIV patients. Eur Respir J. 2012; 39(4):971-8.

3. Thomas CF Jr, Limper AH. Pneumocystis pneumonia. N Engl J Med. 2004; 350(24):2487-98.

4. Tasaka S, Tokuda H, Sakai F, Fujii T, Tateda K, Johkoh T, Ohmagari N, Ohta H, Araoka $\mathrm{H}$, Kikuchi $\mathrm{Y}$, et al. Comparison of clinical and radiological features of pneumocystis pneumonia between malignancy cases and acquired immunodeficiency syndrome cases: a multicenter study. Intern Med. 2010; 49(4):273-81.

5. Wright TW, Gigliotti F, Finkelstein JN, McBride JT, An CL, Harmsen AG. Immune-mediated inflammation directly impairs pulmonary function, contributing to the pathogenesis of Pneumocystis carinii pneumonia. J Clin Invest. 1999;104(9):1307-17.

6. Huffnagle GB, Deepe GS. Innate and adaptive determinants of host susceptibility to medically important fungi. Curr Opin Microbiol. 2003;6(4): 344-50.

7. Mencacci A, Cenci E, Bacci A, Montagnoli C, Bistoni F, Romani L. Cytokines in candidiasis and aspergillosis. Curr Pharm Biotechnol. 2000;1(3):235-51.

8. Romani L. Immunity to fungal infections. Nat Rev Immunol. 2004;4(1):1-23.

9. Raphael I, Forsthuber TG. Stability of T-cell lineages in autoimmune diseases. Expert Rev Clin Immunol. 2012;8(4):299-301.

10. Carson WF, Kunkel SL. Type I and II cytokine superfamilies in inflammatory responses. In: Cavaillon JM, Singer M, editors. Inflammation: From Molecular and Cellular Mechanisms to the Clinic. Weinheim: Wiley-VCH Verlag GmbH \& Co. KGaA; 2017. p. 587-618

11. Montagnoli C, Bacci A, Bozza S, Gaziano R, Mosci P, Sharpe AH, Romani L. B7/CD28-dependent CD4+CD25+ regulatory T cells are essential components of the memory-protective immunity to Candida albicans. J Immunol. 2002;169(11):6298-308.

12. Spolski R, Kim HP, Zhu W, Levy DE, Leonard WJ. IL-21 mediates suppressive effects via its induction of IL-10. J Immunol. 2009;182(5):2859-67.

13. Cao S, Liu J, Song L, Ma X. The protooncogene c-Maf is an essential transcription factor for IL-10 gene expression in macrophages. J Immunol. 2005;174(6):3484-92.

14. Licona-Limon P, Kim LK, Palm NW, Flavell RA. TH2, allergy and group 2 innate lymphoid cells. Nat Immunol. 2013;14(6):536-42.

15. Vahedi G, CP A, Hand TW, Laurence A, Kanno Y, O'Shea JJ, Hirahara K. Helper T-cell identity and evolution of differential transcriptomes and epigenomes. Immunol Rev. 2013;252(1):24-40.

16. Nelms K, Keegan AD, Zamorano J, Ryan JJ, Paul WE. The IL-4 receptor: signaling mechanisms and biologic functions. Annu Rev Immunol. 1999;17: 701-38.

17. Coffman RL, Ohara J, Bond MW, Carty J, Zlotnik A, Paul WE. B cell stimulatory factor-1 enhances the IgE response of lipopolysaccharideactivated B cells. J Immunol. 1986;136(12):4538-41.

18. Abubakar A, Malik M, Pebody RG, Elkholy AA, Khan W, Bellos A, Mala P. Burden of acute respiratory disease of epidemic and pandemic potential in the WHO Eastern Mediterranean Region: a literature review. East Mediterr Health J. 2016;22(7):509-22.

19. Alshahrani MY, Alfaifi M, Ahmad I, Alkhathami AG, Hakami AR, Ahmad H, Alshehri OM, Dhakad MS. Pneumocystis Jirovecii detection and comparison of multiple diagnostic methods with quantitative real-time PCR in patients with respiratory symptoms. Saudi J Biol Sci. 2020;27(6):1423-7.

20. Livak KJ, Schmittgen TD. Analysis of relative gene expression data using real-time quantitative $P C R$ and the 2(-Delta Delta $C(T))$ method. Methods. 2001;25(4):402-8.

21. Sepkowitz KA. Opportunistic infections in patients with and patients without acquired immunodeficiency syndrome. Clin Infect Dis. 2002;34(8): 1098-107.

22. Iriart X, Witkowski B, Courtais C, Abbes S, Tkaczuk J, Courtade M, Cassaing S, Fillaux J, Blancher A, Magnaval JF, et al. Cellular and cytokine changes in the alveolar environment among immunocompromised patients during Pneumocystis jirovecii infection. Med Mycol. 2010;48(8):1075-87.

23. Wright TW, Johnston CJ, Harmsen AG, Finkelstein JN. Analysis of cytokine mRNA profiles in the lungs of Pneumocystis carinii-infected mice. Am J Respir Cell Mol Biol. 1997;17(4):491-500.

24. Masur H, Ognibene FP, Yarchoan R, Shelhamer JH, Baird BF, Travis W, Suffredini AF, Deyton L, Kovacs JA, Falloon J, et al. CD4 counts as predictors of opportunistic pneumonias in human immunodeficiency virus (HIV) infection. Ann Intern Med. 1989:111(3):223-31.
25. Qureshi MH, Harmsen AG, Garvy BA. IL-10 modulates host responses and lung damage induced by Pneumocystis carinii infection. J Immunol. 2003; 170(2):1002-9.

26. Helweg-Larsen J, Jensen JS, Dohn B, Benfield TL, Lundgren B. Detection of Pneumocystis DNA in samples from patients suspected of bacterial pneumonia--a case-control study. BMC Infect Dis. 2002;2:28.

27. Stansell JD, Osmond DH, Charlebois E, LaVange L, Wallace JM, Alexander BV, Glassroth J, Kvale PA, Rosen MJ, Reichman LB, et al. Predictors of Pneumocystis carinii pneumonia in HIV-infected persons. Pulmonary complications of HIV infection study group. Am J Respir Crit Care Med. 1997;155(1):60-6.

28. Doyle L, Vogel S, Procop GW. Pneumocystis PCR: It Is Time to Make PCR the Test of Choice. Open Forum Infect Dis. 2017;4(4):ofx193.

29. Morris A, Sciurba FC, Norris KA. Pneumocystis: a novel pathogen in chronic obstructive pulmonary disease? Copd. 2008:5(1):43-51.

30. Fan LC, Lu HW, Cheng KB, Li HP, Xu JF. Evaluation of PCR in bronchoalveolar lavage fluid for diagnosis of Pneumocystis jirovecii pneumonia: a bivariate meta-analysis and systematic review. PLoS One. 2013;8(9):e73099.

31. Jarvis JN, Casazza JP, Stone HH, Meintjes G, Lawn SD, Levitz SM, Harrison TS, Koup RA. The phenotype of the Cryptococcus-specific CD4+ memory T-cell response is associated with disease severity and outcome in HIV-associated cryptococcal meningitis. J Infect Dis. 2013;207(12):1817-28.

32. Wormley FL Jr, Perfect JR, Steele C, Cox GM. Protection against cryptococcosis by using a murine gamma interferon-producing Cryptococcus neoformans strain. Infect Immun. 2007:75(3):1453-62.

33. Hernandez Y, Arora S, Erb-Downward JR, McDonald RA, Toews GB, Huffnagle GB. Distinct roles for IL-4 and IL-10 in regulating T2 immunity during allergic bronchopulmonary mycosis. J Immunol. 2005;174(2):1027-36.

34. Zhang Y, Wang F, Tompkins KC, McNamara A, Jain AV, Moore BB, Toews GB, Huffnagle GB, Olszewski MA. Robust Th1 and Th17 immunity supports pulmonary clearance but cannot prevent systemic dissemination of highly virulent Cryptococcus neoformans H99. Am J Pathol. 2009;175(6):2489-500.

35. Cenci E, Mencacci A, FdO C, Del Sero G, Mosci P, Montagnoli C, Bacci A, Romani L. Cytokine- and T helper-dependent lung mucosal immunity in mice with invasive pulmonary aspergillosis. J Infect Dis. 1998;178(6):1750-60.

36. Zhang Z, Biagini Myers JM, Brandt EB, Ryan PH, Lindsey M, Mintz-Cole RA, Reponen T, Vesper SJ, Forde F, Ruff B, et al. $\beta$-Glucan exacerbates allergic asthma independent of fungal sensitization and promotes steroid-resistant $\mathrm{T}(\mathrm{H}) 2 / \mathrm{T}(\mathrm{H}) 17$ responses. J Allergy Clin Immunol. 2017;139(1):54-65 e58.

37. Gigliotti F, Limper AH, Wright T. Pneumocystis. Cold Spring Harbor Perspect Med. 2014:4(12):a019828.

38. Procop GW, Haddad S, Quinn J, Wilson ML, Henshaw NG, Reller LB, Artymyshyn RL, Katanik MT, Weinstein MP. Detection of Pneumocystis jiroveci in respiratory specimens by four staining methods. J Clin Microbiol. 2004:42(7):3333-5.

39. Otieno-Odhiambo P, Wasserman S, Hoving JC. The Contribution of Host Cells to Pneumocystis Immunity: An Update. Pathogens. 2019;8(2).

40. Murdaca G, Negrini S, Pellecchio M, Greco M, Schiavi C, Giusti F, Puppo F. Update upon the infection risk in patients receiving TNF alpha inhibitors. Expert Opin Drug Saf. 2019;18(3):219-29.

41. Bruce ES, Kearsley-Fleet L, Watson KD, Symmons DP, Hyrich KL. Risk of Pneumocystis jirovecii pneumonia in patients with rheumatoid arthritis treated with inhibitors of tumour necrosis factor alpha: results from the British Society for Rheumatology biologics register for rheumatoid arthritis. Rheumatology. 2016;55(7):1336-7.

42. Chou CW, Lin FC, Tsai HC, Chang SC. The importance of pro-inflammatory and anti-inflammatory cytokines in Pneumocystis jirovecii pneumonia. Med Mycol. 2013;51(7):704-12.

\section{Publisher's Note}

Springer Nature remains neutral with regard to jurisdictional claims in published maps and institutional affiliations. 